\title{
A Avaliação de Impactes Sociais de Projectos no Quadro do Processo de Avaliação de Impactes Ambientais Reflexões em Torno das Condições de Operacionalização de um "Modelo de Análise" 1
}

Paula Rodrigues *

\begin{abstract}
$\mathrm{R}$ de Avaliação de Impactes Ambientais (AIA) institucionalizado em Portugal, tem-se revestido de algumas dificuldades, quer por razões associadas à própria estabilização do quadro teórico e metodológico da "avaliação social" no contexto das ciências sociais, quer pela existência de constrangimentos relacionados com os contextos culturais e organizacionais da AIA. Considerando o Estudo de Impacte Ambiental (EIA) o instrumento, por excelência, de suporte à tomada de decisão na fase de Procedimento de AIA, propõe-se uma reflexão crítica sobre o lugar que nele tem ocupado a avaliação de impactes sociais, tomando como caso ilustrativo os termos de referência da Componente Social que constam do Caderno de Encargos da Estradas de Portugal - EPE (EP-EPE) para a realização de EIA de infra-estruturas rodoviárias em fase de estudo prévio.
\end{abstract}

Palavras-chave: impactes sociais; impactes ambientais; avaliaçäo de impactes; estudos prévios de estradas.

\section{A Problemática Ambiente/Sociedade nos Processos de AIA: os contextos desta relação}

A reemergência do conceito de sustentabilidade impõe, a vários níveis da intervenção sobre o território, um sério debate sobre a integração das dimensões ambiental, social e económica nas políticas, programas, planos e projectos de desenvolvimento. Ou seja, há razões para acreditar que o primado do "ambiente", na sua versão restrita, cumpriu um papel histórico fundamental na tomada de consciência sobre os "limites ecológicos" da actividade humana (Dunlap, 1993), mas que uma nova era se deverá iniciar, sob pena de se enfraquecerem as potencialidades de compreensão da "sociedade de risco" $"$ em que vivemos e de pro- moção de um desenvolvimento biofísico e humano equilibrado e socialmente equitativo.

Passemos, agora, para uma evidência: a absorção administrativa e política do movimento ecologista, como modo de limitar a radicalização de uma "consciência ecológica", em simultâneo com uma "ecologização" da decisão política em sede de avaliação de impactes de grandes obras (Craveiro, 2002), o "atraso estrutural" de uma "cultura da participação" (quer nas organizações, quer na sociedade civil), a arbitrariedade de exercício de alguns poderes e a excessiva "funcionalização" dos procedimentos administrativos, entre outros factores, têm vindo a constituir constrangimentos profundos à definição de estratégias e ao planeamento e programação de intervenções, integradas

\footnotetext{
* Socióloga, Mestre em Sociologia do Território. Integra o Gabinete de Ambiente da Estradas de Portugal - EPE. Contacto: Paula.Rodrigues@estradasdeportugal.pt

' Este artigo segue de perto a Comunicaçāo intitulada "A componente social nos estudos de impacte ambiental de projectos rodoviários: reflexäes

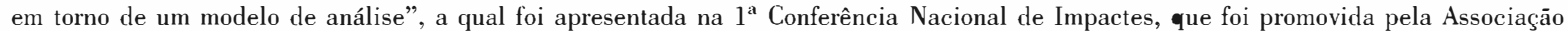
Portuguesa de Avaliaçāo de Impactes (APAI) e decorreu em Aveiro de 3 a 5 de Novembro de 2004.

2 Para uma discussāo de fôlego sobre o conceito de "sociedade de risco", consultar, nomeadamente, Giddens (1992) e Beck, Ulrich (1986, 1992).
} 
e concertadas, que visem o desenvolvimento sustentável dos territórios.

Pode, contudo, considerar-se que a "encruzilhada" em que Portugal "globalmente" se encontra constitui uma oportunidade verdadeiramente inadiável para incorporar novos conceitos e novas práticas de intervenção sobre o território (por exemplo, Avaliação Estratégica de Impactes, Estratégia Nacional para o Desenvolvimento Sustentável, Agenda 21 Local) $)^{3}$.

É neste contexto que se afigura pertinente voltar (porque, efectivamente, não se trata de uma primeira vez) a enfatizar a importância da dimensão social nos processos de avaliação de impactes, tendo presente que em Portugal, a Avaliação de Impactes Sociais (AIS) não se encontra institucionalizada, sendo as preocupações de ordem social integradas no âmbito do Processo de Avaliação de Impacte Ambiental (AIA) ${ }^{4}$.

Estamos perante um vasto campo de reflexão. Mas o presente texto deixa de fora, desde logo, as questões relacionadas quer com a Consulta Pública, quer com a Pós-Avaliação - ambas elementos integrantes da própria definição da Avaliação de Impactes Sociais (AIS) ${ }^{5}$ - para se focalizar nas condições de operacionalização da Componente Social nos Estudos de Impacte Ambiental (EIA), tomando como caso de análise o seu tratamento no âmbito dos Estudos Prévios de infra-estruturas rodoviárias ${ }^{6}$.

Pode parecer que reflectir sobre o lugar e o papel específico da predição de impactes sociais nos Estudos de Impacte Ambiental, enquanto principal instrumento técnico de apoio à decisão no quadro do Procedimento de AIA, constitui um desafio menor, porventura ultrapassado, face aos desígnios e aos objectivos da Avaliação de Impactes Sociais (AIS), mas, volvidos quinze anos desde a consagração do regime de avaliação de impacte ambiental em Portugal, fica-nos a certeza de que persistem os condicionalismos inerentes à sua assunção prática.

De facto, não é exagero considerar que sobretudo no caso de obras de grande envergadura, como sejam as infra-estruturas rodoviárias, os poderes públicos e privados, em particular o dono da obra, a Administração Central e as equipas técnicas se encontram "sensibilizados" para a importância da dimensão social da Avaliação de Impactes.

A sua crescente legitimação decorre da constatação de que ${ }^{7}$ :

- As obras de grande envergadura são geradoras de impactes sociais não conhecidos ou mal conhecidos;

- A médio e longo prazo, esses impactos sociais mal conhecidos ou não esperados podem vir a revelar-se de maior significado que os identificados previamente;

- Na maioria das situações, as mais-valias para o "interesse colectivo" correspondem a impactes negativos directos e indirectos de forte intensidade ao nível social local;

- O sistema da livre concorrência não consegue resolver, adequadamente, o problema da "justiça social";

- É necessário responsabilizar os poderes públicos e privados pela garantia de qualidade de vida dos cidadãos;

- Quanto maior for o conhecimento da população local quer dos impactes negativos quer dos benefícios associados à obra, maior o grau de adesão ao projecto e de aceitação dos custos sociais gerados;

- Aos actores locais e à população, enquanto produtores de práticas e representações sociais sobre o território, cabe um papel inalienável na

\footnotetext{
3 Ver, a propósito do primeiro tema, Partidário, Maria do Rosário (2004) e, do segundo tema, Entrevista a Viriato Soromenho Marques sobre a Estratégia Nacional para o Desenvolvimento Sustentável, na revista Água \& Ambiente, n. ${ }^{\circ}$ 71, OUT2004.

4 O regime jurídico da avaliação de impacte ambiental foi, pela primeira vez, consagrado em Portugal através do Decreto-Lei n. ${ }^{\circ} 186 / 90$ de 6 de Junho, o qual foi revogado pelo Decreto-Lei n. ${ }^{\circ}$ 69/2000 de 3 Maio. Recentemente, foi publicado o Decreto-Lei n. ${ }^{\circ}$ 197/2005 de 8 de Novembro que altera e republica aquele diploma.

${ }^{5}$ Ver, a este propósito, IAIA (2003).

6 Têm como objectivo o estudo de soluções alternativas de traçado, desenvolvidas à escala 1:5000. Caso se trate de um projecto abrangido pelos Anexos I e II ao Decreto-Lei n. ${ }^{\circ}$ 69/2000 de 3 de Maio, como é o caso da generalidade dos projectos da Rede Rodoviária Nacional, o EIA do Estudo Prévio é sujeito a Procedimento de Avaliação de Impacte Ambiental (AIA) para emissão da Declaração de Impacte Ambiental (DIA) e aprovação, de entre as alternativas apresentadas, de um corredor de $400 \mathrm{~m}$ (200m para cada lado do eixo da via). Esta faixa de terreno, que se constituirá como zona de servidão non aedificandi, ficará reservada até à definição do traçado em projecto de execução, fase ainda sujeita a Pós-avaliação Ambiental, no âmbito da qual será submetido a aprovação o Relatório de Conformidade Ambiental do Projecto de Execução (RECAPE). 7 Veja-se, a propósito, Santos (1992).
} 
identificação/negociação das medidas de minimização mais apropriadas face às transformações socioterritoriais previsíveis e verificadas.

Todavia, ao nível do quadro procedimental da avaliação de impactes ambientais coexistem "factores contextuais" que têm representado "factores de regulação" concorrentes para a menorização do estatuto das ciências sociais.

Desde logo, do ponto de vista da conceptualização paradigmática ambiente-sociedade no âmbito do actual quadro legislativo, continua a não se assumir, com clareza:

- a existência de uma relação de mútuo condicionamento entre modelos sociais e modelos naturais;

- que, na sua génese, os problemas ambientais são, fundamentalmente, problemas sociais (condições ambientais e intervenções no ambiente como resultado e com efeitos nas lógicas societais e na vida social) e

- que qualquer intervenção no território opera sempre transformações sociais concretas e "vividas", que não podem ser escamoteadas por uma visão essencialista" do homem e das relações homem-natureza. Uma rápida leitura quer do Decreto-Lei n. ${ }^{\circ}$ 69/2000 de 3 de Maio, quer da Portaria 330/2001 de 2 de Abril, que fixa as normas técnicas para a estrutura da proposta de definição do âmbito do EIA (PDA) e do EIA, permite sustentar esta afirmação ${ }^{8}$.

Acresce que a noção de "ambiente social" constante da referida Portaria, embora necessariamente abrangente, apresenta uma partição temática interna relativamente confusa, permitindo perpetuar, no que especificamente à Componente Social dos EIA respeita, uma lógica de descentramento dos seus nós problemáticos (quando colocada a par de outras componentes, como o Património Cultural, por exemplo). Efectivamente, o "ambiente social" engloba os itens população e povoamento, património cultural, condicionantes, servidões e restrições, sistemas ou redes estruturantes, espaços e usos definidos em instrumentos de planeamento e socioeconomia (Anexo II, ponto 3 IV, ii)).

Do lado propriamente dito da "apreciação técnica dos EIA", pode questionar-se a preparação dos técnicos ou a sua presença, designadamente de sociólogos, face à importância das funções que estão acometidas às Comissões de Avaliação por via da "certificação científica" das decisões políticas que normalmente ocorre quando se trata de projectos estruturantes de nível nacional. Mas o que importa agora reter é que, também elas - as decisões políticas -, em termos do seu modus operandi e dos conteúdos que privilegiam, se inscrevem na perspectiva de enfatização do "primado do ambiente" e das ciências naturais, perspectiva tributária, aliás, das exigências europeias em matéria de conservação da natureza (por exemplo, Rede Natura 2000) e da visibilidade social, mesmo que pontual, de questões ambientais que têm originado queixas contra o Estado Português, por parte de grupos ecologistas.

No caso dos Estudos Prévios de infra-estruturas rodoviárias, uma análise sumária dos Aditamentos aos EIA solicitados pelas Comissões de Avaliação (para efeitos de avaliação da Conformidade do EIA e eventual prosseguimento do Procedimento de AIA) permite observar uma ausência quase total de referências à Componente Social e, quando estas existem, alguma discricionariedade nas apreciações técnicas elaboradas, o que, certamente, não poderá ser justificado pela boa qualidade do trabalho desenvolvido neste descritor, quando, aliás, não são conhecidas quaisquer orientações/directrizes por parte do Instituto do Ambiente quanto a "metodologias de avaliação" para esta Componente dos EIA. Em muitos casos, verifica-se, aliás, que os "impactes sociais" só vêm a ganhar significado e o estatuto de "indicador" à luz das questões levantadas na fase de "Consulta Pública"9.

\footnotetext{
${ }_{8}$ Veja-se, por exemplo, os parâmetros que devem ser tomados em linha de conta na determinação da alternativa ambientalmente mais favorável e as especificações preconizadas para os programas de monitorização (Anexo II da Portaria 330/2001 de 2 de Abril, ponto 3 , V, i) e VI, b)).

9 Não é o âmbito deste texto a eficácia da "Consulta do Público" como acção constante do Processo de AIA, embora sejam reconhecidas as suas fragilidades. O actual regime de avaliação de impactes ambientes não define um modelo de consulta pública nem de "auscultação pública". Valerá a pena, pois, referir que são privilegiadas formas demasiadamente formalizadas e rígidas de participação da população (balcões de atendimento para prestação de esclarecimentos e comentários com validade apenas por escrito), que limitam a apropriação da obra e do EIA, seus custos e benefícios, por parte da mesma. No âmbito da Consulta Pública, as Câmaras Municipais e representantes da sociedade civil por elas convidadas são ouvidas, em reunião, caso a Comissão de Avaliação assim o entenda, com proibição de registo (acta, gravação audiovisual, etc.).
} 
Do lado das equipas técnicas que elaboram os EIA, são reconhecidos os clássicos problemas de tempo e orçamento reduzidos, a que se associa uma prática de trabalho de extrema racionalização dos recursos humanos, de enorme segmentação disciplinar dos temas abordados e de investimento prevalecente nas áreas "duras" do ambiente. Esta configuração da organização do trabalho dificulta a performance sociológica nos EIA, dado que as avaliações sociais são geralmente custosas e morosas.

Ademais, se atentarmos na (nem sempre consensual) relação proponente - equipas técnicas, pode aferir-se que uma das principais questões, senão a principal, reside no facto da avaliação de impactes sociais, pelas próprias características do campo sociológico, não "olhar" a realidade social de um posto de vista tecnocrático e instrumental. Por isso, tende sempre para reflectir sobre os conflitos de interesses e os compromissos que se vão entretecendo entre os vários intervenientes no processo. Essa reflexão, se bem que possa ter vindo a constituir uma condição da relativa situação de "marginalidade" do lugar dos sociólogos no processo, comporta, em si mesma, um conjunto de virtualidades capazes de contribuir significativamente para a construção de uma "teoria da avaliação social"e, sobretudo para a sua afirmação, enquanto dispositivo que, ao introduzir mecanismos de participação cívica, possui, indissociavelmente, um papel de regulação de conflitos.

Internamente ao campo disciplinar da Avaliação de Impactes Sociais, reconhece-se, todavia, que há, ainda, muito a fazer em termos da estabilização dos seus referenciais teóricos e metodológicos. A dificuldade em conceber as bases teóricas para uma efectiva "teoria da avaliação social", que dê corpo a um conjunto articulado e coerente de conceitos, com proveniências disciplinares e filiações teóricas diversas, está patente na (in) definição conceptual e na multiplicidade de abordagens e classificações possíveis dos impactes sociais. Por isso, afigura-se como essencial a definição de um conjunto de procedimentos que corresponda a um modelo de análise passível de ser apropriado e manuseado pelos sociólogos em geral, e aperfeiçoado em função do conhecimento produzido. Este é um desafio colocado a todos os cientistas sociais que, de uma forma ou outra, desenvolvem a sua actividade na área da avaliação de impactes.
O presente artigo incidirá, de seguida, sobre (i) a problemática da abordagem social no âmbito dos EIA e (ii) sobre uma apreciação crítica do modelo de análise proposto pela EP-EPE para a formulação da Componente Social no âmbito dos EIA de infra-estruturas rodoviárias, quer do ponto de vista do dispositivo, quer das condições da sua aplicação. Trata-se, contudo, de uma abordagem exploratória e preliminar das problemáticas enunciadas.

\section{A Componente Social e os Estudos de Impacte Ambiental (EIA)}

\section{Os pressupostos}

Valerá a pena começar por clarificar algumas das dificuldades, internas ao campo disciplinar e de afirmação exterior, com que se tem debatido a Sociologia no que respeita à Avaliação de Impactes Sociais.

A dificuldade fulcral remete para a complexidade do processo de previsão dos fenómenos sociais. Como refere Guerra (1994:5), "Do ponto de vista sociológico, afrontam-se "correntes de pensamento, mais ou menos 'positivistas', que atribuem diferente importância às regularidades de funcionamento societal de onde decorreriam as 'leis' de funcionamento de uma sociedade e, portanto, a capacidade de previsão dos fenómenos. De facto, a complexidade das variáveis que influenciam os fenómenos sociais torna difícil detectar as causalidades indispensáveis a uma análise de avaliação dos impactes sociais." As causalidades são múltiplas e organizam-se segundo um jogo singular de articulações, bem como é bastante elevada a probabilidade de ocorrerem efeitos inesperados (efeitos perversos e/ou elementos de serendipidade).

Outra dificuldade remete para a própria natureza dos impactes sociais, propícia a uma abordagem qualitativa, cruzada e não linear, no sentido em que é frequente os impactes na esfera do social não serem passíveis de uma avaliação "mensurável" e resultarem de efeitos sinérgicos, cumulativos e indirectos. No domínio do social não existem critérios de avaliação universais, mas experiências que se acumulam e que, com relativização, podem ser transportadas de uma realidade social para outra. A necessidade de se construírem instrumentos de medida não pode ofuscar a impossi- 
bilidade de tornar "objectivo" aquilo que é, por natureza, "subjectivo", pois nem todos os impactes são susceptíveis de medição.

Esta dificuldade encontra equivalente ao nível da definição das medidas de minimização, pois que não só é falacioso conceber uma correspondência unívoca entre os impactes e as medidas, como estas tendem a sugerir acções conjuntas que envolvem um xadrez de "actores institucionais" e a participação dos grupos sociais afectados, implicando a desmontagem de "pressupostos ideológi$\cos$ " e a ruptura com práticas tradicionais de segmentação de "competências" e de desvalorização/inoperatividade das "culturas de participação".

"É preciso reconhecer os limites da previsão social e da capacidade de "medição" dos fenómenos sociais na medida e visto que a teoria social tem uma capacidade de previsão limitada" (Guerra, 1994:7).

O reconhecimento da pertinência da contribuição disciplinar da Sociologia para a realização de Estudos de Impacte Ambiental não pode deixar de entroncar no reconhecimento da validade, mas, sobretudo, especificidade da sua proposta teórico-metodológica.

A par disto, necessário será dizer que, em nossa opinião, o desenvolvimento de metodologias de avaliação social cada vez mais adequadas às necessidades dos EIA, passará por:

- Assumir o carácter de "estudo de caso" que cada EIA contempla. Cada projecto ou obra deverá suscitar uma "investigação aplicada", cujo quadro teórico-metodológico esteja adequado à realidade socioterritorial em causa;

- Conformar a lógica de elaboração dos EIA a uma metodologia de planeamento, de que se destaca, desde logo, o carácter estratégico e integrado dos impactes e das medidas de minimização. Esta abordagem genérica permitirá tornar mais eficaz a contribuição sociológica e, por conseguinte, o próprio EIA;

- Caminhar para uma intervenção sociológica menos arreigada às metodologias tradicionais de pesquisa e mais adequada a uma abordagem de pesquisa-acção, ou seja, a um enfoque que valorize, no tempo curto, a tomada de decisões para solução de problemas concretos. Deste ponto de vista, a procura de uma maior qualidade e validade científicas da Sociologia neste domínio apela à "imaginação sociológica", "(...) podendo a problemática dos Impactes Sociais inserir-se entre as áreas que no futuro vão colocar a essa ciência, novos desafios nos domínios teórico, metodológico e prático" (Santos, 1992: 69).

\section{Modelos de análise: uma proposta}

Equacionar-se-ão, por um lado, os problemas relacionados com a caracterização da situação existente, em termos das metodologias, das dimensões de análise e dos problemas-chave e, por outro lado, os problemas relacionados com a definição dos impactes e das medidas de minimização quanto à sua adequação, integração e aplicação estratégica ${ }^{10}$.

\section{A caracterização da situação existente}

$\Rightarrow 1^{\circ}$ Passo: Diagnóstico da Situação Existente e Prospectivo

Propõe-se a elaboração de um Diagnóstico (uma "radiografia") da Situação Existente e Prospectivo que enquadre e dê pistas sobre as questões-chave que o projecto irá colocar, no sentido de se construir o modelo de análise da situação existente ajustado ao projecto e aos contextos socioterritoriais com que eventualmente interferirá.

\footnotetext{
${ }^{10}$ O EIA compõe-se de três etapas formalmente estabelecidas: caracterização da situação existente, definição e caracterização de impactes e proposta de medidas de minimização.
} 
Poderá ter como "guião" o seguinte conjunto de questões:

\section{Âmbito}

- Qual a justificação para este projecto?

- Quais são os objectivos deste projecto?

- Que entidades públicas e privadas envolve?

Identificação dos Problemas, das Mudanças e da sua Importância Relativa

- Quais são os efeitos esperados directos do projecto sobre as diferentes dimensões da vida das populações afectadas?

- Quais são os efeitos esperados indirectos do projecto sobre as diferentes dimensões da vida das populações afectadas?

\section{Elaboração de Perfis Sociais}

- Quais são os grupos sociais que serão afectados e como o serão?

- Quais são as expectativas dos diferentes grupos face à intervenção e quais são os valores que lhe estão subjacentes?

- Quais serão os conflitos potenciais que o projecto desencadeará?

Minoração/Potenciação

- Qual é a melhor alternativa?

- Que medidas de atenuação podem ser tomadas?

- Que medidas de potenciação podem ser tomadas?

- Quais os mecanismos de informação, participação e consulta que se poderão prever?

A construção do Diagnóstico deverá resultar de metodologias que valorizam o "trabalho de grupo", sendo que esta abordagem preliminar implica, genericamente, a utilização das seguintes fontes de informação:

- contactos com informantes privilegiados (científicos e "actores" locais);

- reconhecimento do terreno;

- análise documental e estatística.
$\Rightarrow 2^{\circ}$ Passo: Definição das Dimensões de Análise

As dimensões e subdimensões de análise que configuram o âmbito dos impactes sociais deverão ser seleccionadas e ajustadas a cada tipo de projecto e às questões-chave identificadas no Diagnóstico Preliminar, ou seja, devem ser ajustadas caso a caso, de acordo com os contextos locais e os factores de impacte dos projectos. 
Teoricamente, poderemos considerar as seguintes dimensões e subdimensões de análise:

\begin{tabular}{|ll|}
\hline \multirow{2}{*}{ Dinâmica e composição demográfica } & Evolução populacional \\
Atitudes e representações face ao projecto & Movimentos populacionais \\
& Estrutura etária \\
& Variáveis microdemográficas \\
Serviços prestados à população/equipamentos & Condições de ensino \\
colectivos & Condições de saúde \\
& Redes de equipamentos colectivos \\
& Condições de habitabilidade \\
Habitat & Modelos de produção do habitat \\
& Formas de apropriação do habitat \\
& Indicadores de “conforto e bem-estar" \\
& Emprego e condições de inserção no mercado de trabalho \\
Estruturação económica e socioprodutiva & Níveis de rendimento e consumo \\
& Diversificação e especialização sectorial das actividades económicas \\
& Composição social (estrutura de classes e posições sociais) \\
Identidades sociais (territorializadas) & Memória histórica e especificidades socioespaciais \\
& Inserções territoriais/especializações funcionais \\
& Associação, participação e solidariedade social \\
Atitudes e representações face ao projecto & Grau de aceitação (aceitação/recusa/resistência) \\
& Tipo de apreciação (favorável/desfavorável/indiferente) \\
&
\end{tabular}

\section{$\Rightarrow 3^{\circ}$ Passo: Definição dos Níveis de Análise}

A Definição dos Níveis de Análise não pode deixar de merecer uma atenção cuidada por parte dos especialistas sociais que elaboram Estudos de Impacte Ambiental, pois constitui um dos parâmetros onde mais se tem feito sentir o desajustamento entre os requisitos do Estudo e o trabalho sociológico, com implicações importantes na consequente identificação dos impactes e das medidas de minimização.

No âmbito de um EIA, a escala local constitui o primeiro nível a reter na Avaliação de Impactes Sociais, correspondendo à "área de acção" do empreendimento, sendo de esperar que nela os impactes sejam mais directos, mais objectivos e mensuráveis. Ainda assim, consoante o projecto em causa este nível local poderá ser desdobrado, desde logo destacando a "área de implantação" do projecto da sua "envolvente próxima".

Esta definição do nível local é, desde logo, uma necessidade analítica pois que, "Tratando-se de um trabalho sociológico, este problema torna-se mais complexo já que se pretende avaliar os impactes nos actores sociais e na sua relação ne- cessária com o espaço. Como é sabido, não há, normalmente, coincidência entre contornos sociais e contornos espaciais, tal como raramente existe, no território, contiguidade entre residência, local de trabalho e propriedade fundiária, por exemplo, o que dificulta uma delimitação dos níveis de espaço" (EIA do Sistema Hidraúlico Odeleite - Beliche, Anexo IX - Sociologia, 1994:4).

Efectivamente, há que estar atento ao facto de que os impactes com maior significância, sejam eles em sentido negativo ou positivo, podem, por um lado, não coincidir com recortes espaciais preestabelecidos, nomeadamente o local, e, por outro lado, ser de natureza qualitativa e indirecta e não se subordinarem a avaliações "directivas", "objectivas" e "mensuráveis". Contudo, também não podemos deixar de assinalar que a afirmação dos especialistas em ciências sociais no campo da Avaliação de Impactes Sociais no âmbito dos EIA, passa necessariamente pelo aprofundamento da análise local e pela identificação dos impactes mais determinísticos face à obra, porque são os mais apropriáveis, dotados de maior visibilidade e, sobretudo - se tal for o caso - melhor transponíveis para medidas de minimização concretas a implementar no tempo curto. 
Outros níveis de análise mais globais remetem, genericamente, para abordagens de "enquadramento". Por isso, a sua definição não poderá ser feita num vazio empírico, podendo situarem-se desde o nível de freguesia, ao de concelho, ao de agrupamento de concelhos, ao de subregião, ao de região, ou mesmo a outros de maior amplitude.

$\Rightarrow 4^{\circ}$ Passo: Definição dos Métodos e Técnicas a Utilizar

No âmbito da Caracterização da Situação Existente, o leque de modalidades de produção de informação disponível é bastante diversificado, cobrindo desde entrevistas colectivas, focus-grupos, fóruns comunitários, a técnicas mais clássicas:

- inquéritos por questionário;

- entrevistas semidirectivas;

- análise documental;

- análise estatística;

- observação;

- levantamento de informação no terreno.

Haverá, contudo, que tomar em consideração o seguinte:

- Os Inquéritos por Questionário estarão, a priori, mais ajustados ao nível local do que aos restantes níveis de análise. Normalmente, pelo que envolvem em termos de custos e de tempo, têm sido preteridos no âmbito dos EIA. Por isso, a sua utilização deve encaminhar-se para uma focalização nos grupos sociais identificados na Abordagem Preliminar como mais potencialmente afectados pela obra.

- Os Levantamentos Locais são um instrumento imprescindível de recolha de informação, situando-se, como seria de esperar, ao nível local. Tomemos dois exemplos, particularmente adaptados a projectos que incidam sobre áreas edificadas: a planta funcional da área de intervenção (referenciação cartográfica legendada dos equipamentos colectivos, de unidades económicas e outros espaços relevantes) e a planta de implantação do(s) aglomerado(s) a afectar, nomeadamente contendo a delimitação dos conjuntos habitacionais, a identificação de áreas edificadas particulares e as vias de circulação.
De certo modo, os sociólogos têm sido um pouco avessos a enveredar por este tipo de trabalho de campo; todavia, ele é particularmente útil para caracterizar as "unidades de análise" (estabelecimentos económicos, equipamentos colectivos, condições de habitabilidade, etc.) e clarificar os impactes decorrentes da implantação da obra no terreno que directamente irão afectar o quotidiano das populações locais.

- A Análise Estatística encontra múltiplos problemas de desagregação geográfica da informação, em particular quando se desce à escala local. Relativamente ao INE, principal instituição produtora de dados estatísticos, valerá a pena referir que apenas para 1981, 1991 e 2001 está disponível informação relevante abaixo do nível de lugar (secções e subsecções estatísticas), embora obtida mediante pedidos específicos para o efeito. Ao nível de lugar e, mesmo de freguesia, a informação disponível não publicada é claramente insuficiente, para além de apresentar problemas de compatibilização intercensitária. O elevado custo da informação, normalmente não contabilizado no orçamento do EIA, condiciona também, muitas vezes, a informação que se vai (ou não) tratar. Os Censos podem, como se pode depreender, ser utilizados às várias escalas de análise mas, deverá ser feito um balanço cuidadoso sobre as (im) possibilidades do seu manuseamento à escala local em cada contexto institucional preciso de realização de EIA.

\section{A definição e caracterização de impactes e a proposta de medidas de minimização}

Independentemente das metodologias específicas que podem ser utilizadas e de algumas especificidades disciplinares, também a segunda e terceira Etapas de realização de um EIA voltam a implicar um trabalho colectivo por parte da equipa técnica. Não só a realidade existente e perspectivada não se compadece com abordagens sectoriais dos Impactes e das Medidas de Minimização, como há toda uma "pedagogia" da interdisciplinaridade a fazer, enquanto garante da eficácia e qualidade do Estudo e da sua operacionalização. A este nível, as sínteses e as compatibilizações de informação deverão ser geradas por "ganhos consensuais" e não resultarem do 
trabalho, necessariamente parcial, de uma figura de coordenação.

Em larga medida, os cuidados metodológicos que consideramos como pertinentes para a prossecução destas duas últimas etapas já foram mencionados anteriormente. No entanto, convém assinalar quatro aspectos que não podem deixar de ser equacionados:

- Os níveis de análise dos impactes, no sentido de obstar a dois inconvenientes: o inconveniente de que os pequenos impactes associados à própria actividade de construção da obra (genericamente, incomodidades causadas à população na fase de construção) possam ser valorizados face a impactes indirectos e induzidos mais significativos e de maior alcance; o inconveniente de que os impactes globais do projecto, que normalmente se traduzem numa mais-valia para a população se colectivamente considerada e que por isso acabam por ser considerados positivamente, possam ser valorizados face aos impactes de nível local, os quais trazem, não raras vezes, custos acrescidos para a população directamente afectada.

- As fases do projecto, distinguindo entre "fase de construção" e "fase de exploração", no sentido de demarcar claramente a especificidade da componente avaliativa nestes dois períodos e obstar a que o peso da "fase de construção" prevaleça na definição dos impactes e das medidas.
- O tratamento "compreensivo" e não apenas descritivo dos impactes e das medidas de minimização, não só porque não há necessariamente uma correspondência linear e unívoca entre impacte e medida, mas também porque há, quer para os impactes quer para as medidas, relações internas que importa identificar.

- A eventual consubstanciação de algumas medidas de minimização em "Programas de Intervenção", de modo a dar sentido e coerência a medidas de minimização que, isoladas e pontuais, se revestem de menor grau de eficiência e/ou eficácia.

Antes de se proceder à identificação dos impactes haverá, então que definir o âmbito dos "Factores de Impacte", pois poderá acontecer existirem acções "significativas" que não resultem directamente da construção da obra mas que, por razões várias, com ela estejam associadas e que, por isso, não possam deixar de ser reflectidas no EIA enquanto susceptíveis de causar impactes sociais. O nível de desagregação dos "factores de impacte" é função das características da obra e dos contextos territoriais com que se relaciona. Tanto quanto possível os "factores de impacte" deverão estar afectos a espaços e tempos concretos.

Tal como não há, na comunidade científica, unanimidade relativamente à classificação sectorial de impactes (económicos, socioeconómicos, sociais, culturais), também não há unanimidade nos indicadores utilizados para a caracterização dos referidos impactes. 
Não obstante, e como referência, apresentamos a seguinte grelha:

\begin{tabular}{|c|c|c|}
\hline & e) Segundo a ordenação (a cronologia) & \\
\hline a) Segundo o prazo de incidência & 1. de $1 .^{\mathrm{a}}$ ordem & i) Segundo a magnitude/grandeza \\
\hline 1. de curto prazo & 2. de $2^{\mathrm{a}}$ ordem & 1. muito consideráveis \\
\hline 2. de médio prazo & 3. de $3^{\mathrm{a}}$ ordem & 2. medianamente consideráveis \\
\hline \multirow[t]{2}{*}{ 3. de longo prazo } & $\begin{array}{l}\cdots \\
\text { n. de enésima ordem }\end{array}$ & 3. pouco consideráveis \\
\hline & & j) Segundo o grau de fiabilidade \\
\hline b) Segundo a & f) Segundo o relacionamento & 1. bem conhecidos \\
\hline periodicidade/ritmicidade & 1. directos ou imediatos & 2. razoavelmente conhecidos \\
\hline 1. contínuos & 2. indirectos ou mediatos & 3. pouco conhecidos \\
\hline \multicolumn{3}{|l|}{ 2. descontínuos } \\
\hline c) Segundo a regularidade & g) Segundo o sinal & $\begin{array}{l}\text { l) Segundo o grau de vulnerabilidade } \\
\text { social/abrangência }\end{array}$ \\
\hline 1. regulares & 1. positivos & 1. muito significativos ou amplos \\
\hline \multirow[t]{2}{*}{ 2. irregulares } & 2. negativos & $\begin{array}{l}\text { 2. razoavelmente sinificativos ou amplos } \\
\text { 3. pouco significativos ou amplos }\end{array}$ \\
\hline & & m) Segundo a probabilidade \\
\hline d) Segundo a duração & h) Segundo a & 1. muito prováveis \\
\hline 1. momentâneos & irreversibilidade/sensibilidade & 2. medianamente prováveis \\
\hline 2. temporários & 1. reversíveis & 3. pouco prováveis \\
\hline 3. permanentes & 2. irreversíveis & \\
\hline
\end{tabular}

Fonte: Santos, M., 1992.

Para além da listagem e caracterização exaustiva dos impactes, parece-nos pertinente a elaboração de "Quadros Estratégicos de Avaliação de Impactes Sociais", que forneçam uma leitura expedita dos Grupos Sociais Afectados e dos Campos de Impacte mais significativos em função do seu sentido.

A tipologia de "grupos sociais afectados" é variável consoante as realidades sociais que configuram os sistemas locais de acção, podendo incluir desde população residente, a população activa, a utentes de determinados bens e serviços, a turistas, a grupos socioprofissionais, a "actores" institucionais, etc. A lógica que preside à identificação dos grupos sociais apresenta-se como não exclusiva, mas deverá distinguir as afectações directas das induzidas.

Os "campos de impacte" correspondem a domínios de impacte, ou seja, agrupamentos por tipos de impacte que decorrem das dimensões de análise/áreas temáticas seleccionadas para o projecto em causa, mas que delas se diferenciam pela sua referência explícita ao contexto social local e aos problemas-chave colocados pela implantação da obra.

A construção dos "Quadros Estratégicos de Avaliação de Impactes Sociais" reveste-se de um carácter eminentemente qualitativo e a sua operacionalização depende dos casos em análise.

Deles deverão decorrer "Quadros Estratégicos de Avaliação de Medidas de Minimização". Ainda quanto a estas, a elaboração de "Fichas de Caracterização" parece-nos poder constituir um instrumento útil para a sistematização da informação, fornecendo indicações, no mínimo, sobre a descrição da medida, a sua justificação, os efeitos esperados com a sua implementação e o respectivo faseamento.

A 3. ${ }^{\text {a }}$ etapa do EIA - definição, caracterização e avaliação de medidas de minimização de impactes negativos - corresponde, grosso modo, ao objectivo central que preside à elaboração do EIA, pressuposto que deve estar sempre presente no decurso da sua elaboração. 


\section{A Componente Social nos Estudos de Impacte Ambiental de Infra-Estruturas Rodoviárias: condições, limites e virtualidades}

Em larga medida, este texto resultou da preocupação em maximizar o contributo da Componente Social dos EIA de infra-estruturas rodoviárias em fase de estudo prévio, para a tomada de decisão no âmbito dos Procedimentos de AIA, com vista à adopção da Solução ou combinação de Soluções "ambiental e socialmente mais favoráveis".

No ponto anterior deste artigo propusemos um modelo de análise dos impactes sociais que, em traços gerais e com as devidas adaptações ao facto do objecto de estudo ser uma infra-estrutura linear, não se distancia muito daquele que consubstancia as Clausulas Técnicas do Caderno de Encargos da EP-EPE, tal como se encontram formuladas desde $2001^{11}$.

Ao assumir-se como incontornável o facto de que a Componente Social é, no quadro institucional actual, uma componente "de pleno direito" dos EIA, impõe-se o entendimento de que algumas práticas de trabalho instaladas devem ser contrariadas.

Tradicionalmente, a "Caracterização da Situação Existente" tem-se limitado a uma análise sociográfica (estatística) que, ainda assim, só para um número muitíssimo restrito de indicadores "desce" à escala da freguesia, não apresentando informação suficientemente "localizada" e detalhada para consubstanciar a Avaliação de Impactes e a Análise Comparativa de Soluções, as quais, por essa razão, não espelham a eficácia desejada. Ou seja, impõe-se a necessidade das "dimensões de análise" serem "cruzadas" com diferentes escalas territoriais (unidades espaciais de análise), de que se destaca naturalmente, porque se está perante "Estudos Prévios", o corredor de 400m para cada alternativa em estudo.

Se é consensual admitirem-se abordagens de "enquadramento" que, no nosso entendimento, não devem corresponder à tradicional "caracterização sociográfica" mas situarem-se no quadro de uma "radiografia sociográfica" do posicionamento das freguesias e concelhos directamente afectados pela rodovia em estudo em contextos territoriais mais vastos, a assunção da necessidade de trabalhar ao "nível local da abordagem territorial" - reconhecido que está que os impactes negativos de rodovias, designadamente durante a fase de construção, se situam significativamente a esta escala - não tem sido pacífica, uma vez que implica metodologias de carácter mais intensivo.

\section{Assim, tem-se insistido em que:}

- As temáticas dos aglomerados urbanos/habitação, equipamentos colectivos e actividades económicas constituem o âmago do "nível local da abordagem territorial";

- Importa, relativamente às anteriores três temáticas e para cada Solução, identificar e destrinçar, do ponto de vista estritamente analítico, (i) as situações de afectação directa muito provável (sobreposição com a zona de implantação da estrada), (ii) as situações de afectação directa provável e/ou afectação indirecta muito provável $(7 \mathrm{~m}$ para além do limite da zona da estrada, correspondendo, eventualmente, ao limite da faixa de expropriação) e (iii) as situações de não afectação e de afectação indirecta provável ou muito pouco provável (em termos espaciais corresponderá, eventualmente, à provável zona de servidão non aedificandi e à área restante até ao limite dos $200 \mathrm{~m}$ definidos para cada lado do eixo da estrada);

- O grau de pormenorização da caracterização das unidades funcionais afectadas dependerá da importância daquelas e/ou do tipo de afectação, atendendo a alterações na acessibilidade, alteração da qualidade da função desempenhada e projectos de expansão e/ou relocalização das instalações (no caso de equipamentos colectivos e actividades económicas esta última informação é particularmente importante, não podendo excluir-se liminarmente, como por vezes acontece, o contacto directo com "informantes privilegiados");

- Esta caracterização deverá ser acompanhada de cartografia adequada à escala $1: 25000 \mathrm{e}$ 1:10000 ou 1:5000 (neste caso, poderá preferir-se a fotografia aérea), na esteira de um "levantamento funcional".

\footnotetext{
${ }^{11}$ E que correspondem menos a uma alteração de conteúdo face ao anterior modelo de avaliação de impactes sociais proposto pela EP-EPE (ex-IEP) e mais a uma nova "roupagem", que teve como objectivo dotar de maior coerência interna a abordagem desenvolvida na Componente, por via da procura de uma melhor sistematização e focalização das questões a tratar.
} 
Julga-se, desde já, oportuno argumentar que o facto da directriz e algumas opções técnicas do projecto poderem ser objecto de alteração em fase de projecto de execução, no interior do corredor de $400 \mathrm{~m}$, não retira validade à análise proposta, uma vez que todos os descritores do EIA assumem as soluções estudadas no Estudo Prévio, com o rigor adequado à escala 1:5000. Acresce igualmente que o entendimento tradicional de que as Soluções/traçados só deverão ser objecto de "focalização" na etapa do EIA relativa à avaliação de impactes não se afigura pertinente no âmbito da Componente Social, como aliás, no de outros descritores do EIA. Por um lado, o EIA, efectivamente, não representa uma "história policial" em que se vão dando "sinais" de questões problemáticas ao longo de todo o documento para só se esclarecem, por vezes, na Análise Comparativa de Alternativas, e por outro lado, a identificação e descrição das unidades funcionais afectadas não deverá constituir, em si mesma, um parâmetro da avaliação de impactes sociais.

No domínio dos "Impactes Sociais", observa-se, não raras vezes, que a sua identificação e avaliação se fica pela enunciação de uma tipologia, aplicável a qualquer estrada, quando se afigura essencial fazer o contraponto com a "realidade existente", atendendo à diferente implantação dos traçados em estudo.

Tem-se procurado reforçar a ideia de que as diferentes etapas de desenvolvimento do estudo da Componente Social deverão apresentar encadeamento analítico (enquadramento regional e concelhio $\Rightarrow$ impactes regionais e concelhios; caracterização da área de estudo $\Rightarrow$ impactes locais). Reconhecido que está que não há correspondência entre o "interesse colectivo" e o "nível social local" quanto ao sentido, magnitude e intensidade dos impactes, importa, também, que sejam devidamente identificados e caracterizados, independentemente da fase (se de construção, se de exploração), os impactes sociais mais determinísticos face à obra, porque geralmente são de sentido negativo.

Por outras palavras, tomando em linha de conta a análise efectuada no âmbito da Caracterização da Situação Existente para o "nível local da abordagem territorial" e atendendo às diferentes soluções em análise, o estudo deverá apresentar uma avaliação detalhada das alterações ao nível do tecido socioeconómico, dos serviços básicos (equi- pamentos colectivos) prestados à população e da "qualidade da função habitacional", bem como das alterações nos modos de vida das comunidades locais, considerando que a maior ou menor concentração social dos efeitos do projecto por relação ao grau de heterogeneidade social, à valorização de determinadas representações e práticas sociais, bem como aos constrangimentos e potencialidades associadas à base demográfica, poderão constituir indicadores pertinentes para compreender o real impacte social.

Pode argumentar-se que o Relatório de Conformidade Ambiental do Projecto de Execução (RECAPE) não configura um novo EIA e que, embora algumas situações possam e devam ser reanalisadas em fase de projecto de execução, o Estudo Prévio tem vindo a ser reconhecido, designadamente pelas Comissões de Avaliação, como o "lugar" por excelência do tratamento aprofundado das questões relevantes para a selecção de Soluções (aquelas e não outras que se poderiam "desenhar" na faixa dos $400 \mathrm{~m}$, atendendo a que, em algumas situações muito impactantes se conclui, em sede de estudo prévio, que em projecto de execução não existirá margem de manobra para "ripagens de traçado").

Quanto a "Medidas de Minimização de Impactes Negativos", para além de ser consensual que estas deverão ser equacionadas em função das Soluções que se encontram em estudo e, nessa medida, possuir um grau adequado de concretização espácio-territorial, a EP-EPE tem vindo a propor um grupo de medidas gerais organizadas por:

- Medidas destinadas a estabelecer um "Protocolo" de Comunicação com as Comunidades Locais. Sobre estas importa não perder de vista as que se reportam à "montagem de um sistema de encaminhamento e resposta de queixas e reclamações, de modo a permitir aferir o grau de incomodidade percepcionado pela população residente e equacionar a necessidade de implementação de novas medidas (fases de construção e exploração)" e à "promoção, a montante do início das obras, de acções de informação à população local, sobre a localização, os objectivos, os benefícios e os impactes negativos associados ao projecto, bem como sobre a duração e calendarização prevista para o mesmo, no sen- 
tido de favorecer um maior grau de adesão ao projecto e de aceitação dos custos sociais gerados (antes do início da obra)";

- Medidas destinadas a minimizar os impactes nas Funções Urbanas;

- Medidas destinadas a minimizar os impactes na Mobilidade da População (rede viária).

Estas medidas gerais encontram-se elencadas no Programa de Acompanhamento Ambiental da Obra, o que espelha o interesse da EP-EPE em que as mesmas sejam aplicadas.

Acresce que se afigura pertinente não "descartar" medidas de minimização de impactes negativos para a fase prévia à obra (projecto de execução e/ou início da obra) e recomendações para implementação por parte de outras entidades que não o proponente, desde que devidamente referenciadas e com valor "indicativo".

A indicação, em sede de Caderno de Encargos, de que as medidas poderão ser agrupadas por "Programas de Intervenção" (atendendo, por exemplo à existência de locais sensíveis do ponto de vista social, em que faria sentido equacionar as medidas de modo integrado) e descritas segundo uma "Ficha de Caracterização" construída para o efeito, não foi, até aqui, seguida por nenhuma empresa responsável pela elaboração dos EIA.

Também nenhuma procedeu, tal como preconizado em sede de Caderno de Encargos e no âmbito da Síntese de Impactes do EIA (portanto, já fora do âmbito estrito da Componente Social), a uma Avaliação de Impactes sobre as Comunidades Locais, a par da avaliação global e integrada de todos os impactes identificados. Considerando que os efeitos sobre a "Qualidade de Vida Urbana" decorrentes da construção de uma rodovia não se fazem sentir de modo atomístico, e que a magnitude e significância dos de sentido negativo tendem a ser ampliadas pela percepção subjectiva que a população atingida tem dos mesmos, preconiza-se uma análise integrada das questões sociais e urbano-territoriais e dos problemas ambientais que relevam da dimensão social (particularmente, Componente Social, Planeamento e Gestão do Território, Ruído, Qualidade do Ar, Património e Paisagem), de modo a obter uma visão de conjunto dos impactes sobre as Comunidades Locais e das relações entre eles (simultaneidade, cumulatividade, sinergias).
Se considerarmos o âmbito da avaliação de impactes sociais, podemos concluir que o dispositivo metodológico que tem vindo a ser accionado pela EP-EPE (e pelo que podemos perceber, pela larga maioria dos proponentes e "donos de obra") fica, ainda, muito aquém dos objectivos a ela subjacentes. Deste ponto de vista, poderíamos evidenciar lacunas logo na fase de elaboração do EIA quanto à dimensão de análise "Atitudes e Representações face ao Projecto", dimensão que se encontra ausente do modelo de análise preconizado por se entender que, não existindo condições adequadas para a realização de um estudo específico sobre o Grau de Aceitação (aceitação/recusa/resistência) e Tipo de Apreciação (favorável/desfavorável/indiferente) do projecto e das suas Soluções, com accionamento de técnicas adequadas, poderá ter efeitos perversos uma análise mais ou menos casuística, para um momento dado, necessariamente centrada em "informantes privilegiados" estrategicamente localizados nas redes de "poder" social. Escusado será dizer que as entidades com responsabilidades no território são necessariamente auscultadas durante o processo de estruturação e elaboração do Estudo Prévio e do EIA.

Outras lacunas tenderão, a seu tempo, a ser colmatadas, a principal das quais, pela natureza dos impactes sociais, se prende com a sua monitorização.

Já incluída no regime jurídico de avaliação de impacte ambiental, a pós-avaliação e, designadamente a monitorização que dela é parte integrante, constitui uma dimensão fundamental do processo de avaliação.

De facto, importa retomar o conceito de avaliação, pois, independentemente das perspectivas de abordagem e dos métodos utilizados, esta tem sido encarada como "(...) um conjunto de procedimentos para julgar os méritos de um programa e fornecer uma informação sobre os seus fins, as suas expectativas, os seus resultados previstos e imprevistos, os seus impactos e os seus custos" (Kosecoff e Fink, 1982, cit. in Guerra, 1994:1). A avaliação é “(...) o processo pelo qual se delimitam, se obtêm e se fornecem informações úteis, permitindo ajuizar as decisões possíveis" (Stufflebeam et al., 1989, cit. in Guerra,1994:1) bem como “(...) um aviso sobre a eficácia de uma intervenção ou de um plano que foi experimentado" (Deming, 1983, cit. in Guerra, 1994:1). 
Trata-se, afinal, de introduzir uma componente "reflexiva" em todo o processo de Avaliação, no sentido de melhorar a relação custos/benefícios inerentes.

No campo da avaliação de impactes sociais, dada a relativa incapacidade de controlo directo das principais variáveis da dimensão social, sobretudo em função dos efeitos complexos gerados no decurso das acções, a monitorização assume uma acrescida pertinência, pois coloca a descoberto e dota de maior visibilidade a relação entre as componentes sociais e ambientais (por ex. relação entre actividade piscatória, recursos haliêuticos e qualidade da água) bem como a dimensão social das componentes ambientais (por ex. acústica, paisagem e qualidade do ar).

Interessa, pois, sem descurar outros tipos de avaliação, frisar a necessidade de uma "avaliação processual", isto é, que se faz apelo, nas situações concretas, ao desempenho e às representações dos diversos tipos de actores sociais envolvidos e à integração entre as várias variáveis, enquanto "dispositivos de auto-regulação alargada". É, ao mesmo tempo, "on going" e "ex-post", no sentido em se trata de uma avaliação com fins de acompanhamento e de sistemática "avaliação de impactes".

Por fim, e mesmo considerando as condições e limites quer da cultura organizacional da EP-EPE e dos seus clientes e parceiros, quer do próprio grau de aplicabilidade do dispositivo metodológico que temos vindo a discutir, julgamos que o ganho de estatuto mais visível da Componente Social em articulação com as problemáticas do Planeamento Territorial e do Ordenamento Urbano tem passado por uma precaução que não se baseia na defesa de uma Rede Persona 3000 (por contraponto provocatório com a Rede Natura 2000 e o seu interesse supranacional) mas que tem vindo a sobrelevar a preservação de perímetros urbanos e de modos de vida historicamente sedimentados como "boa prática" de desenvolvimento dos Estudos Prévios e, portanto, da definição das suas Soluções.
Não gostaria de terminar este artigo sem, todavia, propor uma nova pista de reflexão que, creio, é, também, um desafio. Há cerca de 10 anos atrás era relativamente assumido na comunidade científica que não havia, no contexto político-institucional do país, condições institucionais para investir esforços na consagração de dois regimes de avaliação distintos - um, para os impactes sociais e, outro, para os impactes ambientais. A avaliação de impactes sociais (AIS) deveria desenvolver-se no quadro do regime legal da avaliação de impactes ambientais (AIA), que havia sido definido em 1990 e, ainda assim, sem a extensão e profundidade com que se deveriam analisar os impactes ambientais: “(...) num contexto europeu e dada a (relativa) curta experiência dos sistemas nacionais de AIA, o alargamento extensivo e indiscriminado do campo de análise dos EIA àqueles aspectos poderá, por agora ser contraproducente. Na prática, e dadas as evidentes dificuldades metodológicas e susceptibilidade política das matérias tratadas, a inclusão de impactes sociais, económicos, culturais (e psicológicos) poderá vir a enfraquecer, por um efeito de diluição, a própria avaliação das consequências ambientais dos grandes projectos, comprometendo assim o objectivo último dos processos de AIA" (Pinho, 1994: 239).

Creio que este debate tem de voltar a ser feito. Enquanto socióloga e com base na minha experiência profissional, julgo poder afirmar que, se em termos teóricos muitos dos preconceitos das formações científicas naturais e sociais se encontram ultrapassados, a prática demonstra que a avaliação de impactes sociais não tem "espaço" de afirmação suficiente no modelo actual de avaliação ambiental $^{12}$, pelo que é necessário interrogarmonos sobre o melhor caminho: consagrar "explicitamente" a avaliação de impactes sociais no quadro legal da avaliação de impactes ambientais ${ }^{13} \mathrm{ou}$ torná-la independente face ao processo de AIA? $\mathrm{E}$, neste caso, para que projectos, programas e pla-

\footnotetext{
12 Por exemplo, a Monitorização Social, que no âmbito do Processo de AIA tem uma expressão quase nula (o Ruído e a Qualidade da Água são os dois "bastiões" da monitorização feita em Portugal), constitui um dos parâmetros que, decerto, sofreria um incremento exponencial caso a avaliação social tivesse lugar próprio no âmbito de um processo de Avaliação de Impactes.

13 É, por exemplo, a posição defendida no documento "Multistage environmental and social impact assessment of road projects: guidelines for a comprehensive process", produzido pela Comissão Económica e Social para a Ásia e o Pacífico (Nações Unidas, 2001: 9), no qual "To correct the misconception about the restricted meaning of EIA, which is rather widespread among the developing countries in the ESCAP region, it is proposed that a revised term "environmental and social impact assessment (ESIA)", be adopted to stress the need to accord equal emphasis to both the natural and the human environments, and to accurately convey the concern over the negative impacts of road development projects on the human environment".
} 
nos? E que entidade assumiria o papel de autoridade nacional? E que procedimento administrativo adoptar? Embora sejam muitas as questões, considero que persistir no modelo actual, sem, em paralelo, se fazer uma discussão em torno dos con-

\section{Referências Bibliográficas}

AIA - Estudos e Auditorias de Impacte Ambiental,1994, Estudo de Impacte Ambiental do Sistema Hidráulico OdeleiteBeliche, Lisboa.

BECK, Ulrich (1986, 1992), Risk Society. Towards a New Modernity, Londres, Sage.

BURDGE, Rabel J. (coord.), 1994, A Conceptual Approach to Social Impact Assessment, EUA, Wisconsin, Social Ecology Press.

BUTTEL, Frederick H., 1986, "Sociologie et environnment: la lente maturation de l'écologie humaine", Revue Internacionale des Sciences Sociales, n. ${ }^{\circ} 109$, pp. 359-379.

CAPUCHA, Luís, ALMEIDA, João Ferreira de, PEDROSO, Paulo, SILVA, José A. Vieira da, 1996, "Metodologias de avaliação: o estado da arte em Portugal", Sociologia - Problemas e Práticas, n. ${ }^{\circ}$ 22, Lisboa, CIES/ISCTE, pp. 9-27.

CRAVEIRO, João, 1993, Estudos de Impacte Ambiental. Uma Contribuição Sociológica, Lisboa, LNEC.

CRAVEIRO, João, 2002, “A Ecologia Social e a Sociologia do Ambiente: Contributos para uma Ciência com Consciência", in Actas do IV Congresso Português de Sociologia - Passados Recentes Futuros Próximos, APS, Oeiras, Celta Editora $(C D-R O M)$

DUNLAP, Riley, 1993, "From environmental to ecological problems" in CALHOUN, Craig; GEORGE, Ritzer (eds.), Social Problems, Nova Iorque, McGraw-Hill, pp. 707-738.

DUNLAP, Riley; CATTON, William,1983, “What environmental sociologists have in common (whether concerned with "built" or "natural" environments)", Sociological Inquiry, Vol. 53, pp. 113-135.

GUERRA, Isabel, 1994, A Avaliação de Projectos e a Avaliação dos Impactos Sociais, policopiado, Lisboa, CET/ISCTE.

GIDDENS, Anthony, 1992, As Consequências da Modernidade, Oeiras, Celta Editora. textos e das condições associadas à autonomização da avaliação de impactes sociais (AIS), poderá constituir uma "simplificação" e um constrangimento significativo, no tempo longo, ao desenvolvimento sustentável dos territórios.

HIDROPROJECTO,1995, Estudo de Impacte Ambiental da Central de Tratamento de Resíduos Sólidos Urbanos dos Municípios de Amadora, Lisboa, Loures e Vila Franca de Xira, Lisboa.

IAIA, 2003, Social Impact Assessment: International Principles, Special Publication Series, $n^{\circ}$ 2, Fargo, USA, International Association for Impact Assessment.

MORMONT, Marc, 1993, Sciences Sociales et Environement. Approches et Conceptualisations (rapport au Service de la Recherche du Ministère de l'Environement), Arlon, FUL policopiado.

NAÇÕES UNIDAS, 2001, Multistage environmental and social impact assessment of road projects: guidelines for a comprehensive process, Nova Iorque, Comissão Económica e Social para a Asia e o Pacífico.

NESBITT, T. H. D., 1990, "Environmental Planning \& Environmental/Social IA Methodology in the Cross-Cultural Context", Impact Assessment Bulletin, Vol. 8, n. ${ }^{\circ}$ 3, U.S.A., International Association for Impact Assessment, pp. 33-43.

PARTIDÁRIO, Maria do Rosário; JESUS, Júlio (eds.), 1994, Avaliação do Impacte Ambiental, Centro de Estudos de Planeamento e Gestão do Ambiente.

PARTIDÁRIO, Maria do Rosário, 2004, “A avaliação estratégica de impactes em planos de uso do solo", Sociedade e Território, n. ${ }^{\circ} 37 / 38$, Porto, Edições Afrontamento, pp. 183-193.

PINHO, Paulo, 2004, "Impactes Sociais e Económicos" in PARTIDÁRIO, Maria do Rosário, JESUS, Júlio (eds.), Avaliação do Impacte Ambiental, Centro de Estudos de Planeamento e Gestão do Ambiente, pp. 230-240.

SANTOS, Marcos, 1992, "Impactes Sociais: Questões Introdutórias", Economia e Sociologia, n. ${ }^{\circ}$ 54, Évora, Instituto Superior Económico e Social de Évora, pp. 69-89.

TAYLOR, C. Nicholas, BRYAN, C. Hobson, GOODRICH, Colin G., 1995, Social Assessment, Nova Zelândia, Taylor Baines. 